\title{
College student attitudes about telling lies
}

\author{
B. L. KINTZ \\ Western Washington University, Bellingham, Washington 98225
}

\begin{abstract}
Sixty lower division college students (33 female, 27 male) were interviewed individually concerning their attitudes and beliefs about lying. During the interview, which lasted about $40 \mathrm{~min}$ on the average, the students were presented with a sheet of paper on which were listed 12 different social categories of people, for example, politicians, medical doctors, children under the age of 6 years, etc. The subjects were asked to estimate, on a 5-point rating scale, the attitude of the categories of people concerning lying. The scales were labeled from "everybody does it" on one end to "it is wrong in all cases" on the other. In addition, the subjects were presented with six open-ended questions asking them about their personal experiences with their parents, teachers, and others concerning the topic of lying. The answers to these six questions are assigned scale values from 1 to 3 by two judges. Kuder-Richardson reliability of .95 was computed for the ratings; .82 was computed for the question data. Comparisons of the various mean scale values were accomplished by using analysis of variance and Scheffé tests.
\end{abstract}

Politicians have suffered a loss of respect, in the eyes of the voters, during these past few years, or so the popular belief seems to be. Whether H. L. Mencken or Will Rogers would agree that there has been that much of a decline is a topic for a different investigation. The present paper is presented as evidence concerning the viewpoint of certain college students about attitudes toward lying.

In a previous paper (Kintz, 1975), a questionnaire was used to identify people who tend to lie and others who tend to tell the truth. The major investigation in this area was that of Hartshorne and May (1928), who decided that, among the children studied, there was no "deceitful" person at all. They concluded that nearly everyone would lie sometimes, and that hardly anyone would lie under other circumstances.

The present investigation was an attempt to find out what attitudes college students have about lying. The assumption is that attitudes concerning lying have been acquired, and will presumably exert an influence upon whether a person tends to lie.

\section{METHOD}

\section{Subjects}

Sixty lower division undergraduate students (33 female, 27 male) volunteered to serve.

\footnotetext{
Apparatus

A questionnaire listing 12 social categories was prepared. The categories were listed in different quasirandom orders so that no preference would be experimentally produced (see Table 1).

The choice of these particular 12 categories was, of course, somewhat arbitrary, so the list represents only a sample from among many possibilities. Among the researcher's reasons for listing these specific categories were: (1) only 12 were used because it was desired to keep the task small and the time required under $50 \mathrm{~min}$; (2) it was desired to cover a wide age range; (3) professional people who frequently come into contact with others were to be represented, and (4) certain categories were of special, idiosyncratic interest to the researcher.
}

\section{Procedure}

The students were called into the laboratory individually. Each was given the questionnaire and instructed about the task. They were to respond on a 5-point scale representing how favorably they believed verious persons to be inclined toward the topic of telling lies. Low numbers represented negative attitudes and high numbers favorable attitudes. In order to anchor the scale points, phrases were used to describe each: (1) wrong in all cases, (2) usually wrong except "fibs," (3) neutral, (4) usually permissible, especially "fibs," and (5) everybody does it. Each of the 12 categories of people were rated on the 5-point scale.

In addition, six open-ended questions were presented and the students were instructed to write their responses. The six questions are listed in Table 2. The questions were also arranged in quasirandom order for presentation to the students.

\section{RESULTS}

Mean ratings were computed across the 12 categories separately for males and females, and are presented in Figure 1. Analysis of variance showed that there was no

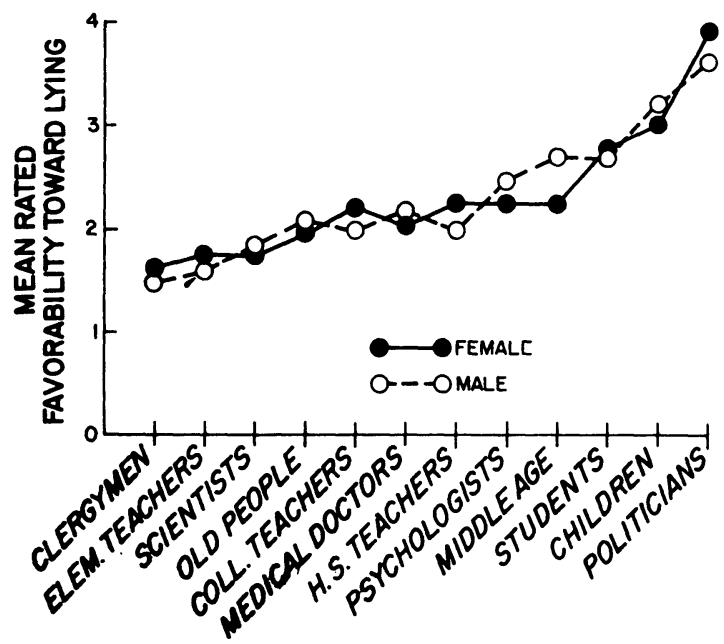

Figure 1. Mean ratings, by males and females, of the 12 social categories. 
interaction between raters' gender and the social categories $[F(11,638)=.885]$. Alpha was set at .01 for all comparisons; the sex of the raters produced no differences beyond chance $[F(1,58)=.0045]$. The categories were rated differently $[F(11,638)=28.415]$. Since there was no interaction, and since the sex of the rater did not produce differences, the data for all 60 students were combined for the rest of the analyses.

On the basis of the mean ratings, the categories were arranged in rank order. The mean ratings for the 12 categories, in rank order, are presented in Table 1.

If these data are to be useful, the rating procedure must be shown to be reliable. The Kuder-Richardson procedure (coefficient alpha) provides information about the internal consistency of the responses. The value of coefficient alpha was computed at .95 , so the students did perform the rating with a good degree of reliability.

The responses to the six open-ended questions were converted to numbers for analysis. Two persons separately judged the responses to fall into one of three numbered categories: (1) lying is not proper, not prevalent, bad; (2) neutral, sometimes done, some people do it; and (3) lying is prevalent, acceptable, favorably regarded. A coefficient alpha of .82 was computed for these judgments, showing lower agreement than for the rating procedure but still being large enough that the

Table 1

Rank Order and Mean Rated Favorability Toward Lying for the 12 Social Categories

\begin{tabular}{lcc}
\hline & Rank & $\begin{array}{r}\text { Mean Rated } \\
\text { Favorability }\end{array}$ \\
\hline Clergymen & 1 & 1.58 \\
Elementary school teachers & 2 & 1.70 \\
Scientists & 3 & 1.80 \\
Old people (over 70 years) & 4 & 2.03 \\
College teachers & 5 & 2.11 \\
Medical doctors & 6 & 2.12 \\
High school teachers & 7 & 2.13 \\
Psychologists & 8 & 2.35 \\
Middle-aged people (40-60 years) & 9 & 2.45 \\
College students (18-20 years) & 10 & 2.75 \\
Children under 6 years & 11 & 3.13 \\
Politicians & 12 & 3.80 \\
\hline
\end{tabular}

Table 3

Significant Scheffe Comparisons $(p<.01)$

\begin{tabular}{lr} 
& \\
\hline & Scheffe \\
& Values \\
\hline Clergy vs. college students & 6.93 \\
Clergy vs. children & 9.19 \\
Clergy vs. politicians & 13.16 \\
Elementary teachers vs. college students & 6.22 \\
Elementary teachers vs. children & 8.47 \\
Elementary teachers vs. politicians & 12.44 \\
Scientists vs. college students & 5.63 \\
Scientists vs. children & 7.88 \\
Scientists vs. politicians & 11.85 \\
Old people vs. children & 6.52 \\
Old people vs. politicians & 10.49 \\
College teachers vs. children & 6.04 \\
College teachers vs. politicians & 10.01 \\
Medical doctors vs. children & 5.99 \\
Medical doctors vs. politicians & 9.96 \\
High school teachers vs. children & 5.93 \\
High school teachers vs. politicians & 9.90 \\
Psychologists vs. politicians & 8.59 \\
Middle-aged people vs. politicians & 8.00 \\
College students vs. politicians & 6.22 \\
Prevalence vs. teachers' statements & 4.90 \\
Prevalence vs. students' beliefs & 6.29 \\
Prevalence vs. parents' statements & 7.67 \\
Someone lies to you vs. teachers' statements & 4.35 \\
Someone lies to you vs. students' beliefs & 5.73 \\
Someone lies to you vs. parents' statements & 7.11 \\
Acceptability vs. parents' statements & 4.70 \\
\hline
\end{tabular}

data may be usefully considered. The mean judged ratings for the six questions are presented, in rank order, in Table 2.

The analysis of variance computed for the data produced results similar to those for the previously presented rating data, viz., no interaction $[\mathrm{F}(5,290)=1.189]$ nor sex effect $[F(1,58)=4.66]$, but differences among the answers to the six questions $[F(5,290)=19.142$.

Post hoc analyses among the mean ratings and among the judged values for the six questions were done using Scheffé tests. The significant differences are presented in Table 3 . These students clearly believed that politicians are a separate breed insofar as their attitude toward lying is concerned.

Table 2

Rank Order and Mean Judged Antipathy Toward Lying for the Six Questions

\begin{tabular}{lcc}
\hline & Rank & Mean Judged Value \\
\hline How prevalent do you think lying is among the general population? & 1 & 1.62 \\
Do you ever find that you know someone is lying to you? & 2 & 3 \\
Is lying an accepted form of social behavior? & 4 & 2.70 \\
What do you remember your teachers telling you about lying? & 5 & 2.33 \\
What are your thoughts about lying? & 6 & 2.53 \\
What do you remember your parents telling you about lying? & 2.73 \\
\hline
\end{tabular}




\section{DISCUSSION}

That these students could reliably rate the social categories of people concerning their attitudes toward lying is apparent. The students clearly believed that politicians have the least negative attitude toward lying. They believed that clergymen have the most negative attitudes. For some reason they believe that psychologists are not too unfavorably inclined. Whether this latter attitude stems from experience in the clinic, in the classroom, or from some other source is of considerable interest.

The responses to the open questions show that these students tend to remember their parents as being against lying, but that lying is quite prevalent in the general population. Further, the students say that they are opposed to lying, but rate their peers as being rather favorably inclined toward lying.

The extent to which lying takes place as a normal social activity is up for question. It might seem from a normal day's activity that many people lie very often. The usual social "white lies" are engaged in because, otherwise, life would be less pleasant. When teachers ask students why they missed an exami- nation, both parties sometimes seem to expect that a "story" is in order. More serious, of course, advertisers seem prone to exaggeration, if not outright lying. Indeed, politicians would often alienate voters if they stuck strictly to the truth. And, since in the last analysis voters get the kind of politicians they want, perhaps voters need to hear the issues presented with hyperbole and the solutions to problems sugar coated for easier swallowing.

\section{REFERENCES}

Hartshorne. H.. \& May, M. A. Studies in deceit. New York: Macmillan. 1928.

KinTz. B. L. Lying on a test and in the laboratory. Bulletin of the Psichonomic Society. 1975, 6. 207-209.

(Received for publication August 22. 1977.) 